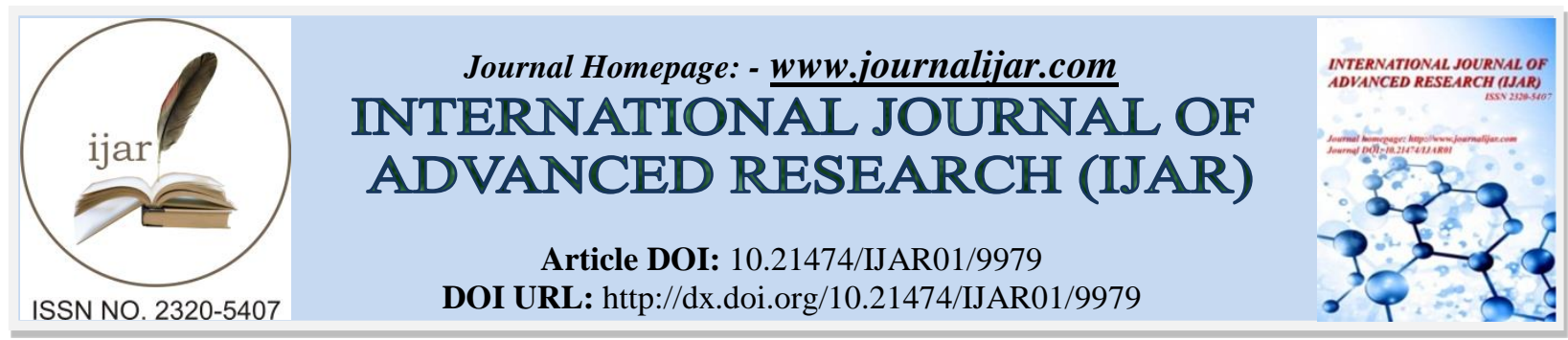

RESEARCH ARTICLE

\title{
MOTIVATION TO LEARN FOREIGN LANGUAGES THROUGH CONTENT BASED TEACHING.
}

\section{Sirojiddinova Shahribonu Sirojiddinovna ${ }^{1}$ and Salimova Nafosat ${ }^{2}$.}

1. English teacher at the chair of English language and literature of the Samarkand State Institute of Foreign Languages, Uzbekistan.

2. Second year student of the faculty of English. Samarkand State Institute of Foreign Languages, Uzbekistan.

\section{Manuscript Info}

Manuscript History

Received: 05 September 2019

Final Accepted: 07 October 2019

Published: November 2019

\section{Key words:-}

motivation, instrumental motivation,

integrative motivation, extrinsic and

intrinsic motivation, foreign language.

\section{Abstract}

Motivation is a frequently encountered term in both daily life and work, and it is considered to be an essential factor that can greatly effect individual's accomplishments and motivation has inseparable role in learning any foreign language. And this research paper reveals the relevance of motivation in terms of acquiring knowledge in the sphere of linguistics.

Copy Right, IJAR, 2019,. All rights reserved.

\section{Introduction:-}

Humans are considerably tiny and weak creatures between the glorious sky and the enormous earth, comparing other creatures, though, their pre-eminent and superior position on this planet can be identified by their possession of species-specific strengths, notably large and complicated brain, and the capacity for sophisticated communication through languages, which is deeply connected with, among other factors, curiosity. All human attitude, behavior and abilities, including capacity and desire for learning, derive the propeller from the internal fundamental force which is often identified by the term "motivation". Motivation is considered to be one of the pivotal areas for human psychology, especially in this rapidly growing area.

"Motivation" and "learning" are two notions often connected in psychology that are believed to fill and support each other. Hebron (1998), one of the leading researchers in the field of motivation in learning, asserts:

"Since motivation and learning are so closely integrated in a continuous process, the two concepts must be considered together. It is obvious that the learning of today enters into the motivation of tomorrow." [1]

Albeit the term "motivation" was no longer normally used until the beginning of this century, the causes and reaction of human behavior and have preoccupied many thinkers and philosophers ever since ancient times. And both Greek and Romanian philosophies were based on "dualist" principle, which is explained by two internal factors that pushes and controls human behavior, and these aforementioned two factors are identified as 'body' and 'soul'. And the body was thought to be controlled by passion - a characteristic shared with animals - but the soul was run by reason and was enable, by the help of knowledge and free will, to differentiate the good from bad, beautiful from ugly. And Aristotle named it as wisdom, and he implied the wisdom to be a way to happiness.

And motivation has become widespread and developed from:

Corresponding Author:-Sirojiddinova Shahribonu Sirojiddinovna.

Address:-English teacher at the chair of English language and literature of the Samarkand State Institute of Foreign Languages, Uzbekistan. 
“... the picture of an organism being pushed around by forces and habits to the alternative of one capable... of taking in information from its internal physiology, its physical environment and, most of all in Man, its social environment." (Evans, 1975) [5]

And nowadays motivation is frequently used word in daily life and study as well, and a teacher is able to encourage his/her students by saying "Given motivation, anyone can learn a language", and it shows that in language learning, motivation is crucial, and even same as to intelligence, desire to learn and aptitude, motivation is capable of influencing greatly the achievements of students in their second language or foreign language learning acquisitions. As motivation is also regarded as a second significant predictor of success, trailing only aptitude, it would be vital to acknowledge what the notion of motivation is in terms of learning foreign language. And it would be more appropriate to commence talking about motivation in terms of learning any foreign language with one of the most well-known definitions of language:

"Language is a purely human and non-instinctive method of communicating ideas, emotions and desires by means of a system of voluntarily - produced symbols. These symbols are, in the first instance, auditory and they are produced by the so - called organs of speech" (Sapir, 1921) [1]

Speaking about the research conducted on "motivation", the most outstanding contributors in this field - Gardner and Lambert and their co-workers, since they accomplished the most important work. They commenced their study in the 1980s and they revealed two primary types of motivation and they named them as "instrumental motivation" which occurs when the learner has a functional goal in learning a foreign language, such as to obtain a higher occupation or to get promoted, or to pass an examination, to meet the educational or vocational requirements, to use in their holiday or to get relevant data in their target language and to exploit the representatives of the foreign culture whose language they are attempting to learn; and the latter is "integrative motivation", which occurs when a learner desires to identify and learn the history, culture, national values of the nation thoroughly. Comparing these aforementioned sorts of motivation, researchers believed that the perfect and superior motivation is integrative motivation owing to the fact that is more competent and well - organized.

Students, who possess neither instrumental nor integrative motivation, in fact, are likely to encounter an array of hardships in learning and gaining knowledge of a second language on the course of studying or in general, learning any language will be burdensome for them.

A foreign language is something that might seem to be more challenging to learn than any other field of science, such as mathematics or physics, as a foreign language is not considered to be the part of science. It requires more effort, desperate intention from a learner and can be learnt on the course of particular period of time. In our country, ranging from the initial years of the Independence till today's contemporary period, the primary attention of the government is being dedicated to learning foreign languages, particularly English, and myriads of accomplishments have been fulfilled in this field. To illustrate, most of the students are getting involved in exchange programs, foreign experts and tutors are invited to contribute the process and etc. Notwithstanding, it is quite melancholic fact that our country still stands in the lower stages on the list that shows the English knowledge level of the countries' population. Approaching differenty to the process of teaching foreign languages, especially English, is therefore crucial that in order to promote our country's fame in the global stage, we firstly have to alleviate people's knowledge on English, as this language has already become the major lingua-franca around the globe. And moreover, according to the data yielded by this study, around $80 \%$ of all information in the world is maintained in English, and it indicates that in terms of any sphere one definitely needs English.

During the process of teaching English, students might get demotivated due to the fact that the pronunciation, syntax and lexicology of this language is quite unfamiliar to our native language, and for this reason, so as to push the learners to make an attempt to read, spell, practice the language out loud motivation from teachers' side can be the best propeller. Other researchers of this field, Ryan and Deci, also introduce divergent types of motivation which are called "extrinsic motivation" and "intrinsic motivation". Students who have intrinsic motivation are able to be easily tied up with various activities since intrinsic motivation is an eagerness and intention to accomplish and to take part in some certain activities because an individual regards them as essential and attractive.

Students with intrinsic motivation are thought to stay stable with intricate and sophisticated situations and obtain knowledge from their slips and mistakes. 
Extrinsic motivation, on the other hand, is desire to get involved in any activity or occasion due to the rationale that are no longer normally connected with the activity itself. These rationales might be the anticipation of reward or penalty, like succeeding in examination and getting good score.

To come to the point, intrinsic motivation is a will to do an activity because of itself. In fact, the individuals who are intrinsically motivated accomplish any activity and assignment out of their own excitement. They fulfill everything because they assume that they are enjoyable. Those who are extrinsically motivated are vice versa, they are motivated to do a work or an activity as means of acquiring something. They perform and do affairs as they think that their effort and contribution will equip them in terms of being rewarded, getting tutor's admiration, or evasion (prevention) of punishment.

Motivation is a fundamental and vital part of learning. Gardner (1885), believes that with the intention of being motivated, the learner necessitates, requires and needs to have something anticipate, foresee, expect and long for, a reason, principle, or rationale having to do with aim or target. In terms of second language acquisition, this propeller would be learning a foreign language. As a matter of fact, there must be something that the learner intends to obtain or do, being the target language the vehicle to attain it.

Cook (2000) states that acquisition of language is not in the same level among all learners. He also states that there are three main factors which influence second language acquisition and these three factors are; age, personality and motivation. Motivation is the most significant factor among the mentioned three factors.

As a four-year-learner of the English language, I noticed that, most of the tutors in ESL classes in our country still follow the primitive general translating method, which has already regarded as less effective. And in this case, my personal suggestion to ameliorate the contemporary state is to alter the strategy and methods of teaching languages. In ESL classes, tutors should not be like the teapot that pouring the knowledge into students' minds, and the learners also should become more active and get associated with their peers, instead of idling and being the mute members of the process. To say more precisely, teachers should develop themselves first from aristocrats, that continuously order their students, to democrats, that are almost always efforts to encourage the students to interact, get involved with the rest of the class; teachers have to become not the speaker, yet listener of the students' ideas; guiding lights that lead and reveal the right directions to the students, and finally teachers should motivate the students to seek for the knowledge on their own, instead of trying to give them all the knowledge, which is naturally impossible. In fact, teachers have crucial role in motivating ESL learners, and for this reason they also have to be aware of both extrinsic and intrinsic motivation and how they are formed, captured, and finally, how they are displayed in the learners. In order to create and develop both types of motivations in learners, the teacher ought to keep the classroom quiet and without anxiety. Providing educational and academic advantages, motivating students, and asking simple and easy questions at the beginning of class (before asking difficult questions) are able to raise motivation for learning in students.

According to the experiment that we, accompanied by our students in Institute of foreign languages, conducted in order to once reaffirm the significance of motivation in any field, we are able to assert that the role of motivation is crucial in terms of not only learning foreign languages, but also in any field of science, such as medicine as well. Our research was aimed to start the implementation of EMAP (English for Medical Academic Purposes) amongst the students in medical field since this program has already been set in many developed English speaking countries, and we assumed that it is high time for us also. One of the foremost handicaps that we faced was lacking of English knowledge in the students, i.e., so as to instruct them medicine in English, first we have to teach them English Language itself and for this reason we had to make an initial syllabus of teaching basic English to the medical students. For the beginning, we tried to teach basic integrated skills of English such as writing, reading, listening and speaking and we found out that speaking and listening were a bit more difficult than the others and required more effort. In that case, we tried to ask as simple and easy questions as we could, in order not to discourage them or not to make them lose their desire to obtain English knowledge. At the beginning that experience was a bit difficult, or even awkward, yet, as the students could answer the questions, for example, most terms in medicine derive from Latin, which are considered to be internationally used terminology, and so are in English as well, and as they began encountering the familiar words and expressions in English medical passages, they simultaneously started getting more and more curious of the spelling and pronunciation of that words, which motivated the students intrinsically. And as a matter of fact, they began getting more and more satisfied from what they were doing and typically, teaching writing was no longer so difficult for both sides. 
As for listening, we supposed that putting monotonous and long audios concerning their own field was not so profitable for them and therefore we suggested our professors to read fundamental and simpler medical texts out loud in such a way that the students were able to comprehend and communicate with the students in order to alleviate their level and provide them with both extrinsic and intrinsic motivation. And for now, our group is about to commence instructing complicated medical themes in English and use the language in a higher level.

The target of our research was to involve the students in other fields in learning at least English, and for the beginning we experimented it in medical students as knowing and being able to communicate in English can enable them to take part in international conferences, get acquainted and interacted with their foreign colleagues, and apply for both local and foreign workshops and get involved in many student exchange programs as there can be seen a requirement for medical specialists in foreign workshops as well. Being able to communicate at least in English, they are capable of meeting the requirements of foreign educational establishments and occupations as this language opens them a door to many destinations: they can easily be employed, get a job with reasonable or even higher salary, and the most essential, manage to read a myriad of foreign literature and resources according to their specialty and these abovementioned factors were the most primary factors for the students to get both extrinsically and intrinsically motivated during our research.

According to the scholars' assertions concerning motivation, we can come to a conclusion that motivation in second language learning is characterized by several factors: to determine and experience success; to inspire ones interests and to make anyone interested, to make the positive impression about foreign language learning in the students and make them enjoy what they are doing. Motivation in learning foreign languages is totally different and complicated psychological phenomenon, and thus has been attracted and entrusted by many researchers. As the researches show, motivation is highly connected with individual's intellectual abilities, creative and critical thinking through language, and the eagerness. Due to the advanced globalization and modernization, more and more people desire to learn foreign language to equip themselves both in career and life. And for this reason all researchers hope that in terms of teaching and learning a foreign language, motivation will also soon become being considered as one of the most vital pedagogical tools in our country as well.

\section{List of references:-}

1. Allwright, R. L. (1977): "Motivation - the teacher's responsibility" English language teaching journal, $31,2$.

2. Gardner R. C. and Lambert W. E, 1972. Attitudes and Motivation in Second-Language Learning. Rowley, MA: Newbury House.

3. Gardner R. C., 1985. The Role of Attitudes and Motivation. London, Great Britain: Edward Arnold.

4. Wilkins D. A., 1975. Linguistics In Language Teaching. London: Edward Arnold.

5. Bernard, W. (1951): "Psychological Principles of Language Learning and the Bilingual Reading Method". Modern Language Journal, 35, 1.

6. Brown H. Douglas, 1994. Principles of Language Learning and Teaching. USA: Prentice Hall Regents.

7. Cook, V. (2000). Linguistics and second language acquisition. Beijing: Foreign Language Teaching and Research Press and Macmillan Publisher Ltd.

8. Belmechri Faiza and Hummel Kirsten, 1998. Orientations and Motivation in the Acquisition of English as a Second Language Among High School Students in Quebec city. Language Learning 48: 2, p219 - p244

9. Brewer, E. W., \& Burgess, D. N. (2005). "Professors role in motivating students to attend class" Journal of Industrial Teacher Education, 42(3), 24.

10. Hyland K, editor. English for academic purposes. New York: Routledge; 2006. P. 50.

11. Wright R. Medical English debunked. IATEFL Prof. Acad. Engl 2012; 39:39. 